\title{
Identification of a Material-Lubricant Pairing and Operating Conditions That Lead to the Failure of Porous Journal Bearing Systems
}

\author{
Guido Boidi ${ }^{1}$ Stefan Krenn ${ }^{1}$. Stefan J. Eder ${ }^{1,2}$ (])
}

Received: 15 July 2020 / Accepted: 3 October 2020 / Published online: 15 October 2020

(c) The Author(s) 2020

\begin{abstract}
In this study, we perform accelerated wear tests with porous journal bearings (PJBs) on a lab test rig, providing statistically reliable results under realistic operational conditions. To this end, a custom-made tribometer consisting of 5 mechanically independent but centrally controlled units was used to test five identical bearings in parallel. The test parameters were tuned to promote enough wear under mixed lubrication by increasing the clearance gap and the radial load, while minimizing the bidirectional rotational speed. A wide range of lubricant and material combinations were evaluated, the vast majority of which performed excellently (i.e., negligible wear and low friction). Only one notable combination of a low-density iron bearing paired with a standard PAO-based lubricant failed when operating at low rotational speeds, exhibiting highly unstable frictional behavior and 10-20 times the typical wear in practical applications. An analysis of Stribeck curves, recorded periodically during the wear tests as a diagnostic tool, proved that this particular combination of materials and parameters failed to run in properly, with deteriorating tribological behavior over time. A direct relation between the total wear and the maximum temperature in the tribocontact during testing helped identify this pairing as the only one operating solely under mixed lubrication (high asperity contact), explaining the excessive wear.
\end{abstract}

\section{Graphical Abstract}

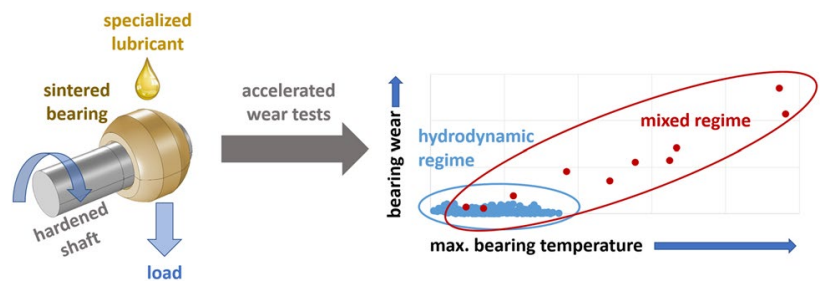

Keywords Porous journal bearing $\cdot$ Mixed lubrication $\cdot$ Friction $\cdot$ Wear $\cdot$ Accelerated wear test

\section{Introduction}

Saving energy and reducing pollutant emissions are not new topics in the scientific community, but the current environmental scenario requires significant attention and suitable engineering solutions. In this context, tribology

Stefan J. Eder

stefan.eder@ac2t.at

1 AC2T research GmbH, Viktor-Kaplan-Straße 2/C, 2700 Wiener Neustadt, Austria

2 Institute of Engineering Design and Product Development, TU Wien, Lehargasse 6 - Objekt 7, 1060 Vienna, Austria plays a crucial role, since many mechanical components are involved in real applications where the relative motion between surfaces leads to friction and wear. The search for green and high-performance lubricants and low-wear materials are a fundamental topic for many research groups in the world, who are striving to improve tribological performance and thus reduce pollutant emissions [1].

Powder metallurgy is frequently utilized for manufacturing journal bearings [2-4]. The porosity obtained after the sintering process is used as an oil reservoir for improving lubrication and preventing starvation. Thus, the main advantage of porous materials is their self-lubricating behavior 
$[5,6]$. Porous journal bearings (PJBs) are impregnated with lubricant to maintain a continuous lubricant supply between shaft and bearing. They operate in the hydrodynamic lubrication regime for most of their lifetime, as long as the pores are still sufficiently filled with lubricant [7]. Under startand-stop conditions (e.g., windscreen wipers $[8,9]$ ) or after long and severe operation, the lubricant regime is more likely to be mixed or boundary lubricated, depending on the quantity of lubricant still present in the pores. More generally, the lubrication mechanisms occurring in soft contacts were extensively studied in $[10,11]$. These findings have improved the understanding of lubrication theory of porous contacts and can aid the design of new porous material combinations in sliding contact.

PJBs have been extensively studied since the 1950s [5, $6,12]$, but new developments are still explored nowadays, such as surface texturing [13] and novel lubricants [14, 15]. The tribological properties of PJBs operating under hydrodynamic lubrication have also been previously studied by some of the authors $[7,16]$ using a single test rig. As PJBs are designed for lifetimes exceeding 10,000 h [17], experimental tests used to be costly, as a single test could go on for several weeks, so a more systematic test approach can reduce testing times and costs. For this reason, some of the authors developed a multi-bearing test rig to be able to test 5 bearings at the same time, an advantage that may be used either for increasing the data acquisition throughput or for obtaining a reliable statistical analysis by testing nominally identical bearing systems in parallel $[18,19]$. Although tribological studies of PJBs are not a new topic in literature, a more in-depth approach is required especially for those operating under harsher conditions such as mixed lubrication.

This work aims at developing such a systematic approach for selecting and designing new material-lubricant combinations for porous journal bearings operating under harsh conditions (high load and low speed). For this purpose, our custom-made test rig for performing parallel tests was used for scrutinizing a wide variety of lubricant and material pairings (material type, density/porosity, and lubricant chemistry variations). At a contact pressure of almost $3 \mathrm{MPa}$, the tribological contact (shaft-bearing) can be considered highly loaded at the rotational speeds encountered in this study, regardless of the exact bearing material. Moreover, the lubrication gap clearance was slightly modified to promote more severe contact conditions, allowing accelerated wear tests ( 5 bearings in $48 \mathrm{~h}$ ) while maintaining operating conditions similar to those in real systems. As we will discuss in the last part of this paper, our high-throughput approach allowed us to ascertain, from a total test matrix including more than 100 pairings and with reliable statistics, that one seemingly standard combination of bearing material and lubricant runs a high risk of failing under mixed lubrication conditions. Since changing only one of the parameters already led to acceptable system behavior, the identification of such a dangerous operating point leading to erratic friction and catastrophic wear would be impossible using standard methods, as the results would likely be treated as an outlier.

\section{Materials and Methods}

The authors provide here only essential information for understanding the experimental procedure and the custom-made test rig, since these aspects have been already presented in previous publications [18, 19]. This paper focuses therefore on the tribological results obtained from
Fig. 1 a Schematic representation of the bearing and shaft; $\mathbf{b}$ visualization of the screening test matrix, where the color denotes the diametric wear of the bearing after the test. The poor behavior of Fe-low combined with PAO gave rise to extended testing near the region marked in white

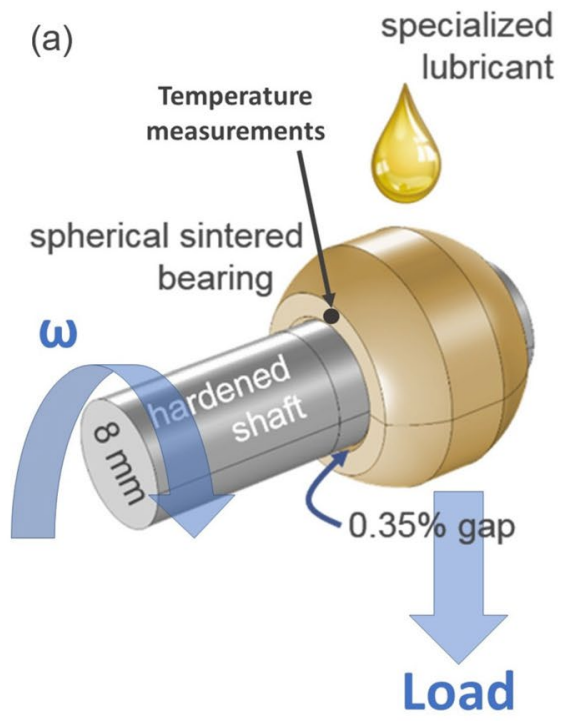

(b)

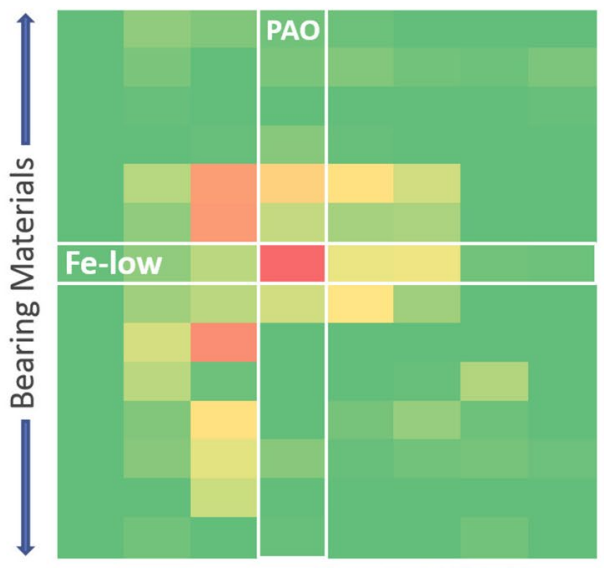

bearing wear (low/mid/high) 
the experimental tests rather than on construction details related to the test rig.

\subsection{Experimental Setup}

The PJBs were first cleaned using toluene and then impregnated with the test lubricant. A standardized routine was developed to ensure cleanness of pores, avoid solvent impurities and also impregnate the bearings in a repeatable way [18]. The density of the PJBs was measured before and after the impregnation by weighing and dividing by the known volume in order to ensure that all the samples were impregnated with lubricant to at least $95 \%$. A hole was drilled in the transverse section of the bearing for temperature measurements (thermocouple) during the tests and also for simplifying and standardized sample positioning, see Fig. 1. The hole position was intended to allow a measurement of the temperature as close as possible to the contact zone without compromising the structural integrity of the bearing. Five samples of the same material, impregnated with the same lubricant were then mounted in the tribometer benches for parallel tests. The measurement signals for evaluation of the Coefficient of Friction $(\mathrm{CoF})$ were continuously recorded during the test with a sample rate of $2 \mathrm{kHz}$ and statistically processed to $5 \mathrm{~Hz}$ time series data in the output file (one average value every 400 points), whereas wear was evaluated after the test.

\subsection{Bearing Materials and Lubricants}

PJB production is a powder metallurgical manufacturing process that consists of four major process steps: mixing, pressing, sintering, and calibrating. Mixing the metal powders together with other alloying elements ensures a homogeneous distribution of the individual materials. Thus, desired material properties can be achieved, and certain process parameters can be specifically influenced. The mixed metal powder is filled into the mold, and subsequently compacted by the press plunger. After its release from the press, the part almost has the final shape, but not yet the required strength. During sintering below the melting point of the alloying elements the part does not melt, but the powder particles merge due to diffusion processes that influence the mechanical properties of the component. Finally, calibration and embossing increases both dimensional accuracy and density while also improving the surface quality of the bearing surface.

Our PJBs were supplied by the manufacturer with an increased diameter gap $(0.35 \%)$ between shaft $(8 \mathrm{~mm}$ in diameter) and the internal diameter of the bearing, see Fig. 1a. This gap was designed to reshape the contact geometry and promote more asperity contact and consequently higher wear (accelerated tests). The spherical bearings had
Table 1 PJB materials and compositions

\begin{tabular}{llll}
\hline & Abbreviation & $\begin{array}{c}\text { Density } \\
\left(\mathrm{g} / \mathrm{cm}^{3}\right)\end{array}$ & Composition \\
\hline Bronze based (Br) & Br-low & 6.8 & Pure bronze \\
& Br-high & 7.2 & Pure bronze \\
& BrGr-low & 6.6 & Bronze $+1.5 \mathrm{wt} \%$ graphite \\
& BrGr-high & 7.0 & Bronze $+1.5 \mathrm{wt} \%$ graphite \\
& BrMo-low & 6.6 & Bronze $+3.5 \mathrm{wt} \% \mathrm{MoS}_{2}$ \\
& BrMo-high & 7.0 & $\mathrm{Bronze}+3.5 \mathrm{wt} \% \mathrm{MoS}_{2}$ \\
Iron based (Fe) & Fe-low & 5.8 & $\mathrm{Fe}+2 \% \mathrm{Cu}$ \\
& Fe-high & 6.2 & $\mathrm{Fe}+2 \% \mathrm{Cu}$ \\
& FeGr-low & 5.8 & $\mathrm{Fe}+3 \% \mathrm{Cu}+1.5 \mathrm{wt} \%$ graphite \\
& FeGr-high & 6.2 & $\mathrm{Fe}+3 \% \mathrm{Cu}+1.5 \mathrm{wt} \%$ graphite \\
& FeCuGr-low & 5.8 & $\mathrm{Fe}+20 \% \mathrm{Cu}+1.5 \mathrm{wt} \%$ graphite \\
& FeCuGr-high & 6.2 & $\mathrm{Fe}+20 \% \mathrm{Cu}+1.5 \mathrm{wt} \%$ graphite \\
& FeGr+-low & 5.6 & $\mathrm{Fe}+1.5 \% \mathrm{Cu}+2.8 \mathrm{wt} \%$ graphite \\
& FeGr+-high & 6.0 & $\mathrm{Fe}+1.5 \% \mathrm{Cu}+2.8 \mathrm{wt} \%$ graphite \\
\hline
\end{tabular}

an external diameter of $15.6 \mathrm{~mm}$ and a length of $11 \mathrm{~mm}$. Martensitic steel shafts were substituted after each test. The shafts had been tempered at $180{ }^{\circ} \mathrm{C}$ for $1 \mathrm{~h}$, resulting in a surface hardness of $650 \pm 10 \mathrm{HV}$ and of $400 \mathrm{HV}$ at $0.7 \pm$ $0.3 \mathrm{~mm}$ depth from the surface.

Bronze and iron-based bearing materials were used. Various quantities of graphite, copper, and molybdenum disulfide $\left(\mathrm{MoS}_{2}\right)$ were added on some configurations to improve solid lubrication. Furthermore, the effect of porosity was studied for every bearing material, with all materials being available in two different effective densities, see Table 1 . The total volumetric porosity of bearings could be estimated based on the material density (inverse relation). For all materials, "low density" corresponds to $25 \%$ of total volumetric porosity, whereas "high density" corresponds to $20 \%$ of total volumetric porosity.

The tribological response of porous materials not only depends on the total porosity, but also on pore characteristics such as average pore dimensions, distribution, connectivity, and shape [20-22]. For this work, the pore area fraction (fraction of area occupied by the pores expressed as a percentage) as a function of pore size was evaluated by optical analysis. The bearing surface images of iron and bronze-based materials at low and high density were carefully analyzed using the open-source software ImageJ [23], see Fig. 2. Three different regions $\left(\simeq 3 \times 1 \mathrm{~mm}^{2}\right)$ of each sample were randomly selected and analyzed to obtain statistically reliable data.

The pores of the low-density iron-based bearing (Felow) were generally smaller than $65 \mu \mathrm{m}$, and the maximum fractional area ( $>2 \%$ ) was covered by pores of $40 \mu \mathrm{m}$ size. For this configuration, there were also some pores of large dimensions (around $90 \mu \mathrm{m}$ ), representing approximately $2 \%$ of the surface. Iron bearings with high density (Fe-high) 
Fig. 2 Porosity analysis of the bearing surfaces of a Fe-low, c Fe-high, e Br-low, and $\mathbf{g} \mathrm{Br}$ high, as well as the corresponding pore size distributions related to the pore area fraction $(\mathbf{b}, \mathbf{d}, \mathbf{f}, \mathbf{h})$
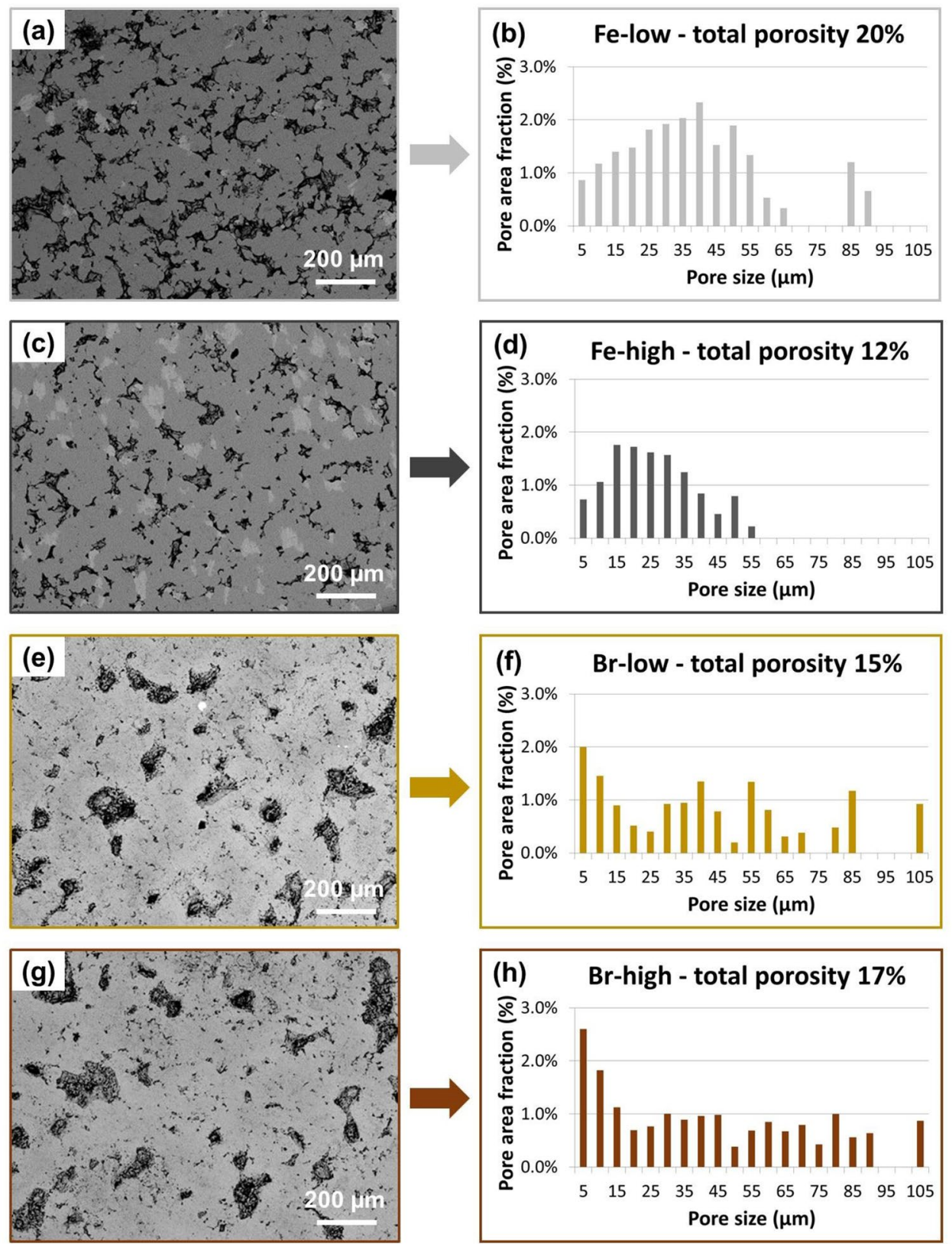

exhibited lower porosity, and pores were generally smaller than those of Fe-low, as expected. Besides that, Fe-high did not present any pores larger than $60 \mu \mathrm{m})$. Bronze bearings had a surprisingly similar total porosity and pore size distribution for both high and low density. Small pore dimensions $(<5 \mu \mathrm{m})$ represent the maximum of the pore size distribution, but quite large pore dimensions (up to $105 \mu \mathrm{m}$ ) were encountered in both bronze materials. The areal porosity distributions were probably so similar for Br-low and $\mathrm{Br}$-high due to the calibration operation at the end of the fabrication process. The mechanical surface compression during calibration likely caused surface deformation and consequently an alteration of the surface porosity, where the bronze materials were more affected than the iron-based ones because of the lower hardness of bronze.

A wide range of synthetic lubricants was used for experimental evaluation, ranging from viscosity index of 143 (PAO) to 326 (PFPE), see Table 2.

To justify the particular bearing-lubricant combinations discussed later on in the text, we give an overview of the wear results obtained from a first high-throughput screening run prior to this study (only one sample per combination) in Fig. 1b. The headers for the rows and columns as well as the exact diametric wear values cannot be given here for confidentiality reasons, but it is clear that the combination $\mathrm{Fe}$ low/PAO performs surprisingly poor when operating in the 
Table 2 Lubricants used for the tribological tests

\begin{tabular}{lllll}
\hline Abbreviation & Lubricant base & Density $\left(\mathrm{g} / \mathrm{cm}^{3}\right)$ & $\begin{array}{l}\text { Viscosity }(\mathrm{mPa}) \\
\left(40{ }^{\circ} \mathrm{C} / 100{ }^{\circ} \mathrm{C}\right)\end{array}$ & Viscosity index \\
\hline PFPE & PFPE + PTFE & 1.9 & $90 / 25$ & 281 \\
PFPE-lin & Linear PFPE & 1.9 & $159 / 45$ & 326 \\
PG & Polyglycol & 1.04 & $46 / 9$ & 181 \\
Ester & PAO-Ester + Li soap & 0.98 & $68 / 14$ & 215 \\
PAO & PAO + Li soap & 0.8 & $55 / 9$ & 143 \\
PAO+Gn & PAO + Li soap & 0.8 & $55 / 9$ & 143 \\
& +0.1 wt $\%$ graphene & & & \\
\hline
\end{tabular}

Fig. 3 a Multiple bearing test wear tribometer and $\mathbf{b}$ schematic representation of a single bench

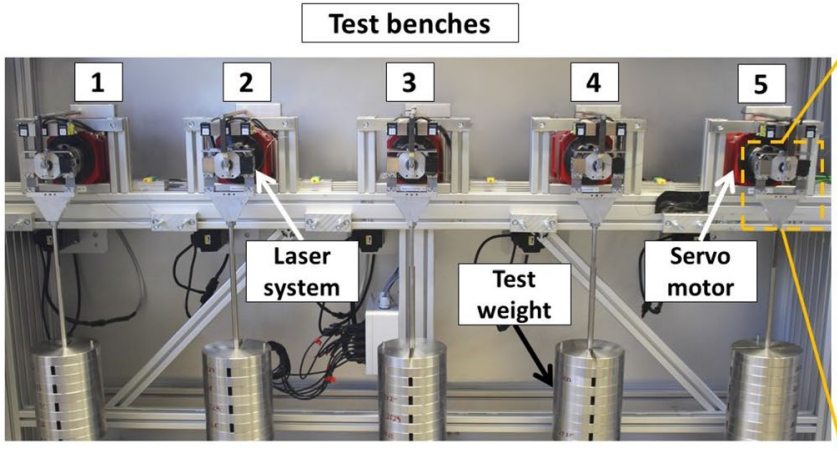

(a)

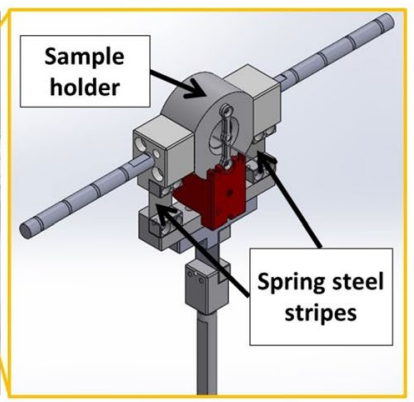

(b) boundary lubrication regime, which is especially noteworthy since this is a standard bearing-lubricant combination. This result, which was originally believed to be either an outlier or a measurement error, led to the in-depth analysis of combinations around the region marked by the white cross.

\subsection{Tribological Experimental Apparatus and Test Conditions}

The tribological tests were performed using our custom-built multiple bearing wear tribometer [18]. The rig consists of 5 identical test benches for performing multiple parallel evaluations, see Fig. 3. The bearings are mounted on a shaft driven by a servo motor. A frequency converter permits continuous speed variation for each servo motor. A dead weight mounted on a rod is used to axially load the bearings (pendulum), see Fig. 3. Limp spring steel strips were used for connecting the rod and the sample holder as well as avoiding axial sliding between bearing and shaft, see Fig 3b. The CoF can be measured either by evaluating the signal of the frequency converter for long-run measurements (low time resolution) or by a laser system that allows recording data at high resolution. The laser system is more accurate and used to measure pendulum deflection as a measure for the friction torque. These two different techniques for measuring the CoF were used in different stages of the tribological test, as will be explained in the following paragraphs. The reader is referred to previous publications $[18,19]$ for more in-depth details on the rig construction and its technical features.

Five wear tests were performed in parallel for each bearing material-lubricant combination. A constant load of $25 \mathrm{~kg}$ was applied in all tests to obtain a contact pressure of approximately $3 \mathrm{MPa}$. In an effort to minimize the time required for producing a measurable and widely comparable amount of diametric wear in the porous journal bearings, we tested and evaluated several speed profiles on a Fe-low bearing impregnated with a low-viscosity PAO lubricant. We compared the effect on total diametric wear of profiles with constant speed, unidirectional, as well as bidirectional saw tooth profiles featuring speed maxima of $20,50,150,300$, and $750 \mathrm{rpm}$. We also checked for the influence of total running time and the addition of a running-in period of $6 \mathrm{~h}$ at $1000 \mathrm{rpm}$. We found that including a running-in period was counterproductive, as it allowed for gentle flattening of initial asperities in the hydrodynamic lubrication regime, but such running-in does not occur in real operation. Furthermore, we found that no appreciable changes in the friction behavior could be observed after approximately $40 \mathrm{~h}$ of testing, and that the highest amount of wear could be produced with the lowest manageable speed. Thus, we arrived at a protocol where the speed varied according to a bidirectional saw tooth profile with a speed maximum of $20 \mathrm{rpm}$ in each direction with a period of $10 \mathrm{~s}$, see Fig. 4a. Each test 
Fig. 4 a Speed saw tooth profile and $\mathbf{b}$ Stribeck ramp performed after $1,2,3,4,5,8,11,14,17$, $20,28,36,44 \mathrm{~h}$ of tests

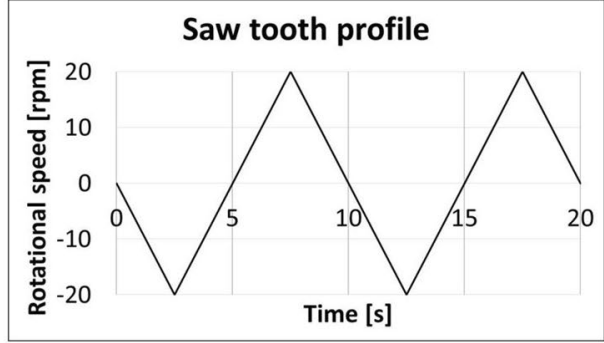

(a)

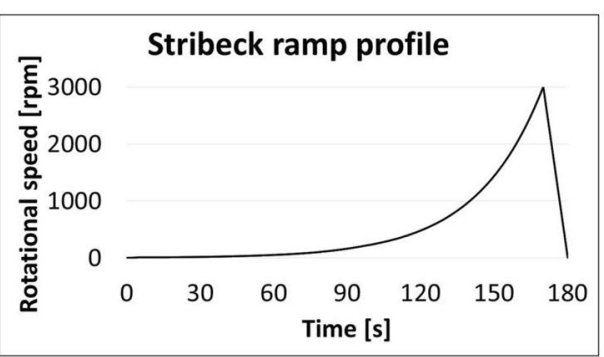

(b)

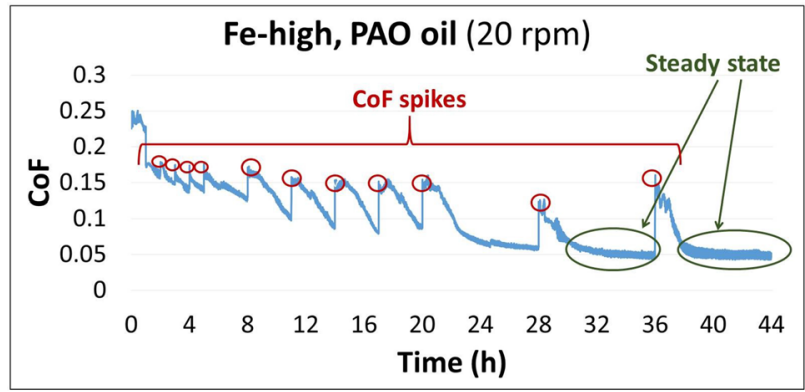

Fig. 5 Example of a coefficient of friction curve measured during the $44 \mathrm{~h}$ test at $5 \mathrm{~Hz}$ sampling frequency

ran for a net duration of $44 \mathrm{~h}$ in this "high wear regime". The saw tooth speed profile was interrupted by Stribeck ramps with exponential speed increase up to $3000 \mathrm{rpm}$ (see Fig. 4b) after fixed time intervals: every hour up to $5 \mathrm{~h}$ of total testing time, then every $3 \mathrm{~h}$ up to $20 \mathrm{~h}$, and finally every $8 \mathrm{~h}$ until completion of the test, yielding a total of 13 interruptions of the saw profile (after 1, 2, 3, 4, 5, 8, 11, 14, 17, 20, 28, 36, 44 h of testing). Each Stribeck curve was recorded three times in a row to ensure statistical reliability. Selected bearing material and lubricant combinations were also evaluated using a speed profile of $50 \mathrm{rpm}$ for appraising a sliding speed effect on tribological behavior. In particular, the speed dependence of wear in the combination of Fe-low with PAO was of high interest, as this pairing performed so poorly at $20 \mathrm{rpm}$.

The coefficient of friction $(\mathrm{CoF})$ was continuously measured during the saw tooth speed profile phases via the signal of the frequency converter, where only the values at $\pm 20 \mathrm{rpm}$ were compared, leading to a sampling frequency of $5 \mathrm{~Hz}$. During the Stribeck ramps, the CoF was recorded at a sampling frequency of $2 \mathrm{kHz}$ via the laser instrumentation that measures the pendulum deflection. Wear was measured using a tactile two-point comparison instrument (Schwenk OSIMESS) after the end of the test in the central and the near-border regions (approximately $1 \mathrm{~mm}$ from external border) of the internal bearing diameter in the inner bearing bores [24].

\section{Results and Discussion}

\subsection{Coefficient of Friction Results}

Figure 5 shows a typical time development of the CoF over the $44 \mathrm{~h}$ testing time, with the Stribeck ramp data removed and the respective interruptions clearly visible as $\mathrm{CoF}$ jumps. The CoF spikes in the graph represent test interruptions in the saw speed profile for performing the exponential speed profile of the Stribeck curves. These speed interruptions caused start-and-stop issues in the contact (starvation), and therefore direct asperity contact and consequently a local CoF increase (spikes). Furthermore, the high speed during the Stribeck profile increased the temperature (see Fig. 10), which led to a viscosity drop and lubricant thinning, subsequently promoting asperity contact and a transient $\mathrm{CoF}$ increase. Following the temperature spikes caused by high speed during the Stribeck curves, the temperature slowly decreased to its previous (ambient) level, see (see Fig. 10a-d). The temperature drop then caused the lubricant viscosity and thus the load support capacity to increase, consequently reducing asperity contact. For these reasons, the $\mathrm{CoF}$ decreased in a similar way as the trend of the temperature, see Figs. 5 and 10b). For all the material and lubricant combinations, we observed that the $\mathrm{CoF}$ reached a steady value after a run-in period. This behavior is mainly due to changes in the contact geometry during the tribological test. Several cycles between the contacting bodies (shaft and inner bore of the bearing) caused asperity flattening, and thus the contact pressure was reduced and a lower $\mathrm{CoF}$ was obtained. The frictional response over time of the high-density steel bearings (Fe-high) tested with reference oil (PAO) is presented as an example for such behavior in Fig. 5. In this case, the CoF assumed a steady value after roughly $30 \mathrm{~h}$ of testing.

The studied material and lubricant combinations showed different levels of CoF, but the general trend was the same (CoF spikes due to test interruptions, running-in in the beginning with higher $\mathrm{CoF}$, and steady $\mathrm{CoF}$ state at the end). For these reasons, a general comparison between all sample combinations was made based on the steady $\mathrm{CoF}$ state at the end of the test $(44 \mathrm{~h})$. Coefficients of friction for each 

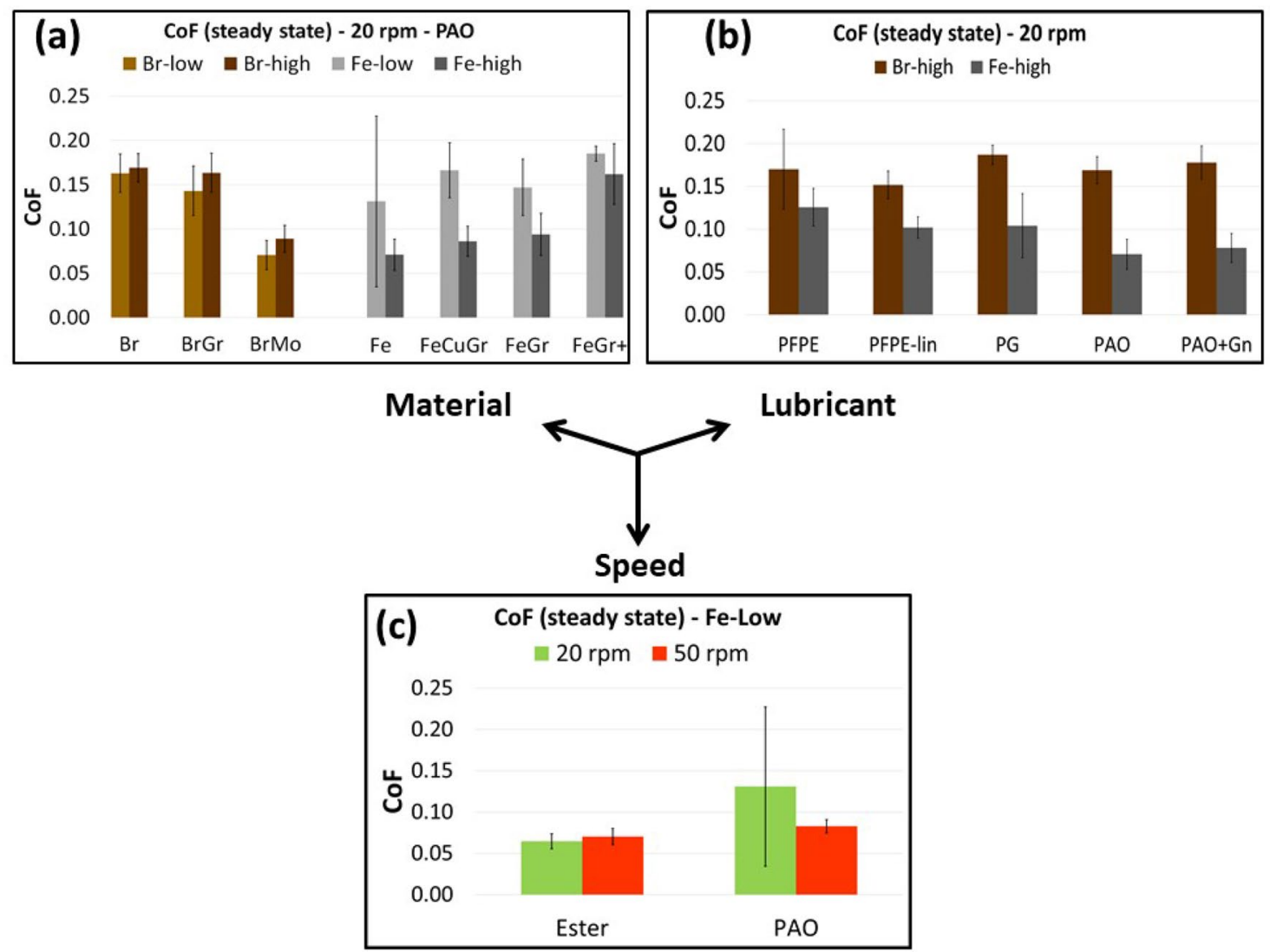

Fig. 6 Coefficient of friction $(\mathrm{CoF})$ in the steady state (end of test) for a material, b lubricant, and $\mathbf{c}$ speed variation

bearing material and lubricant combination were calculated as average of the five identical tests run in parallel on different benches. The main results for the $\mathrm{CoF}$ of the steady state are visualized in Fig. 6. Due to the wide range of studied conditions, the results were grouped according to material, lubricant, and speed variation for improving the interpretation and summarizing the main outcomes, see Fig. 6.

A bearing material variation (Fig. 6a) was evaluated using the synthetic PAO as a benchmark lubricant and a saw profile speed of $20 \mathrm{rpm}$ for all bearing materials. For the bronze bearings ( $\mathrm{Br}$, brown color series in Fig. 6), we found that the addition of graphite (BrGr) slightly improved tribological performance, whereas significant $\mathrm{CoF}$ reduction was achieved by adding molybdenum disulfide $\left(\mathrm{MoS}_{2}\right.$ -BrMo), as expected [25-27]. The two BrMo systems consistently exhibited remarkable running-in behavior, with a drop in the $\mathrm{CoF}$ at $20 \mathrm{rpm}$ from 0.35 to below 0.1 within $8 \mathrm{~h}$ of operation in the case of BrMo-low. As will be mentioned in the next section, these particular systems were also prone to noticeable, but contained changes in the bearing diameter, so the good tribological performance may be a result of a redistribution of $\mathrm{MoS}_{2}$ that was loosely bound in the bearing matrix to the sliding interface, which is accompanied by the smearing shut of pores in the contact region. On the other hand, the addition of a substantial amount of copper $(20 \%-\mathrm{FeCuGr})$ and graphite $(\mathrm{FeGr}+)$ to the iron-based bearing $(\mathrm{Fe})$ brought drawbacks. The increase of copper together with the addition of graphite ( $\mathrm{FeCuGr}$ and $\mathrm{FeGr})$ increased $\mathrm{CoF}$ compared to the reference iron-based material $(\mathrm{Fe})$. However, the worst performance was observed for the material with reduced copper and the maximum achievable addition of graphite ( $\mathrm{FeGr}+$ ), probably because not only the chemical composition was changed but also the density. In this case, $\mathrm{FeGr}+$ bearings exhibited generally lower density than reference iron material $\mathrm{Fe}$, and therefore this behavior could be caused by higher porosity or by lower hardness. It was shown in $[20-22,28]$ that the increase of porosity and pore dimensions generally leads to an increase in friction. Large pores can cause lubricant film breakdown with the consequent increase of asperity contact and $\mathrm{CoF}[21,22]$. The graphite addition in $\mathrm{FeGr}+$ was significantly higher than in the other compositions, especially considering the volumetric content. Since here the graphite is only loosely bound within the bearing matrix, a significantly higher volume of graphite in $\mathrm{FeGr}+$ caused more unsteady tribological behavior. 
Comparing the same bearing material with different densities (low- and high-density series in Fig. 6a), bronzebased bearings showed only small differences, namely that in general low-density materials (Br-low) exhibited lower $\mathrm{CoF}$ values than those with high density (Br-high). However, compared to the differences between the respective results, the error bars on the bronze CoFs are too large for claiming that these differences are statistically significant, and the areal bearing surface porosities between $\mathrm{Br}$-low and $\mathrm{Br}$ high are almost indistinguishable, see Fig. 2e-h. We encountered the opposite behavior for iron-based materials, where low-density materials had increased friction compared to high-density ones. This behavior is again in agreement with $[20-22,28]$, where it was demonstrated that an increase in porosity and pore size (see the iron-based series in Figs. 6a and $2 \mathrm{a}-\mathrm{d}$ ) also increases the CoF. It should also be noted that Fe-low produced highly scattered friction data in combination with PAO, the reasons for which will be discussed in the next sections.

The lubricant variation (Fig. 6b) was evaluated using the high-density bronze (Br-high) and iron-based material (Fehigh), using a saw profile speed of $20 \mathrm{rpm}$. These two bearing materials were chosen in this comparison for their high industrial relevance, as they are frequently used standard components that should be compatible with a wide range of lubricants. The bronze bearings (high density) generally produced higher friction values than iron ones for all tested lubricants, see Fig. 6b. Looking at the results for the bronzebased bearings, it was also observed that the lubricant variation did not lead to significant $\mathrm{CoF}$ changes. For iron-based materials, however, the best results were obtained with the PAO lubricant, which features low viscosity and a low viscosity index.

Finally, a speed increase of the saw profile (from 20 to $50 \mathrm{rpm}$ ) was evaluated (Fig. 6c) only for low-density ironbased material (Fe-low) with ester and PAO lubricant. It was observed that when using ester, the speed variation did not significantly affect the steady $\mathrm{CoF}$ of $\mathrm{Fe}$-low. However, higher speeds $(50 \mathrm{rpm}$ ) significantly reduced the $\mathrm{CoF}$ when using the PAO lubricant. Here, we again mention the high $\mathrm{CoF}$ variation for $\mathrm{Fe}$-low tested at $20 \mathrm{rpm}$ with the PAO lubricant (see also material variation, in Fig. 6a). Reasons for that will be discussed in the next sections.

\subsection{Wear Results}

The total wear for each material was expressed as average values of the measurements taken at the middle and near
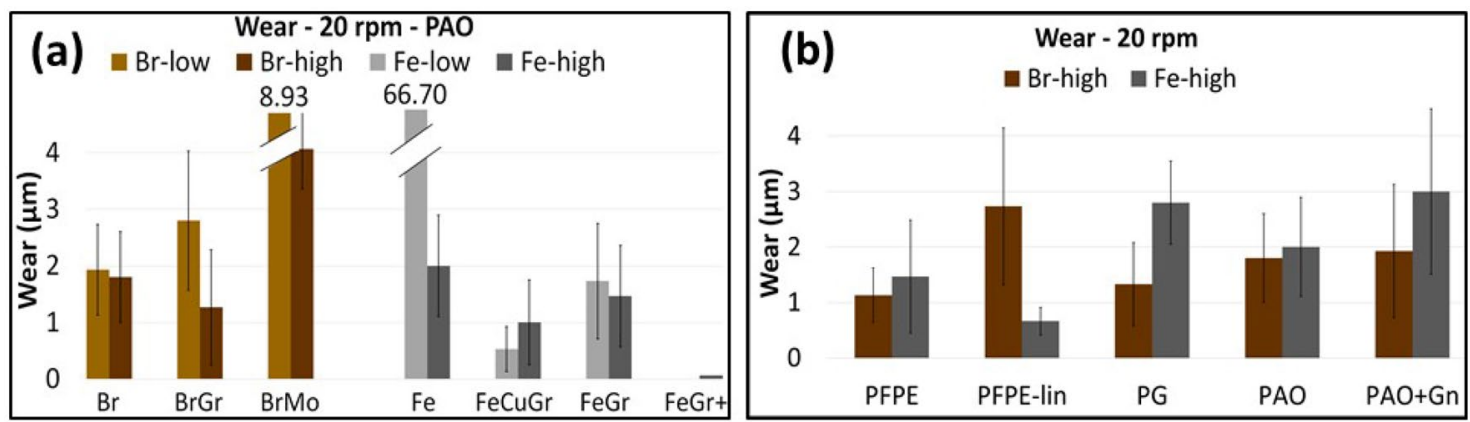

Material

\section{Lubricant}

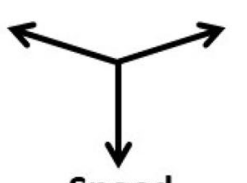

Speed

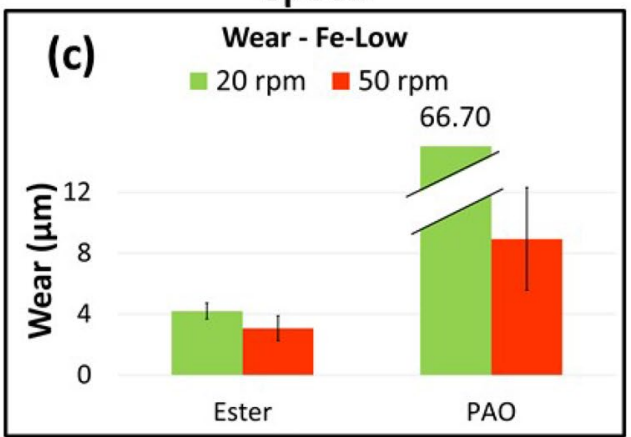

Fig. 7 Wear measured in the inner bore diameter of the bearings after the tests for $\mathbf{a}$ material, $\mathbf{b}$ lubricant, and $\mathbf{c}$ speed variation 
the two edges (approximately $1 \mathrm{~mm}$ from external border) of the inner bore diameter of the bearings. Furthermore, the value obtained was averaged between the five identical samples tested on parallel benches. The main results, grouped according to speed, bearing material, and lubricant variation, are shown in Fig. 7. Before going through the results, it should be mentioned that a diametric wear below $10 \mu \mathrm{m}$ can be considered contained, while values below $5 \mu \mathrm{m}$ are considered an expected effect of running-in and can therefore be neglected.

Generally, the bearing materials tested with different speed and lubrication combinations did not wear out significantly after the $44 \mathrm{~h}$ tests, with the exception of some cases (Fe-low and BrMo-low, PAO lubricant at $20 \mathrm{rpm}$ ), see Fig. 7a. The low-density series of bronze with $\mathrm{MoS}_{2}$ (BrMolow) exhibited contained wear (below $10 \mu \mathrm{m}$ ), whereas the iron-based bearing (Fe-low) produced unacceptable wear (more than $60 \mu \mathrm{m}$ averaged over 10 tested bearings).

For BrMo-low, the "higher" wear (between 5 and 10 $\mu \mathrm{m})$ could be due to higher porosity (lower density material) and due to the solid lubricant $\mathrm{MoS}_{2}$. It was proved in previous works [29-31] that an excessive quantity of solid lubricant may deteriorate mechanical material properties and decrease wear resistance. Furthermore, it should be considered that solid lubricants are primarily added for extreme starved lubrication conditions and they may not work well in combination with some contaminants, e.g., hydrocarbons, water, and oxygen [26, 32]. In the case of Fe-low, the bearing clearly failed during tests, the possible reasons for which will be evaluated in more depth in the next section.

When comparing various lubricants in high-density $\mathrm{Fe}$ and $\mathrm{Br}$ bearings, as shown in Fig. 7b, it can be stated that wear is practically negligible here. The slight trend that $\mathrm{Fe}$ wears more than $\mathrm{Br}$ is only broken for PFPE-lin, but the absolute values are so low and the data scatter for the $\mathrm{Br}$ system is relatively large that a serious discussion about the causes for this behavior is not possible.

It is noteworthy that the increase of speed (from 20 to $50 \mathrm{rpm}$ ) for Fe-low tested with PAO reduced the diametric wear to acceptable values, see Fig. 7c. The increase of speed could bring the system to a less severe regime of lubrication, therefore avoiding direct asperity contact and excessive wear.

\subsection{Investigation of Fe-Low with PAO at 20 rpm}

This section will focus on Fe-low tested with PAO at $20 \mathrm{rpm}$, since this combination exhibited behavior distinctly different from all other combinations both in terms of $\mathrm{CoF}$ and

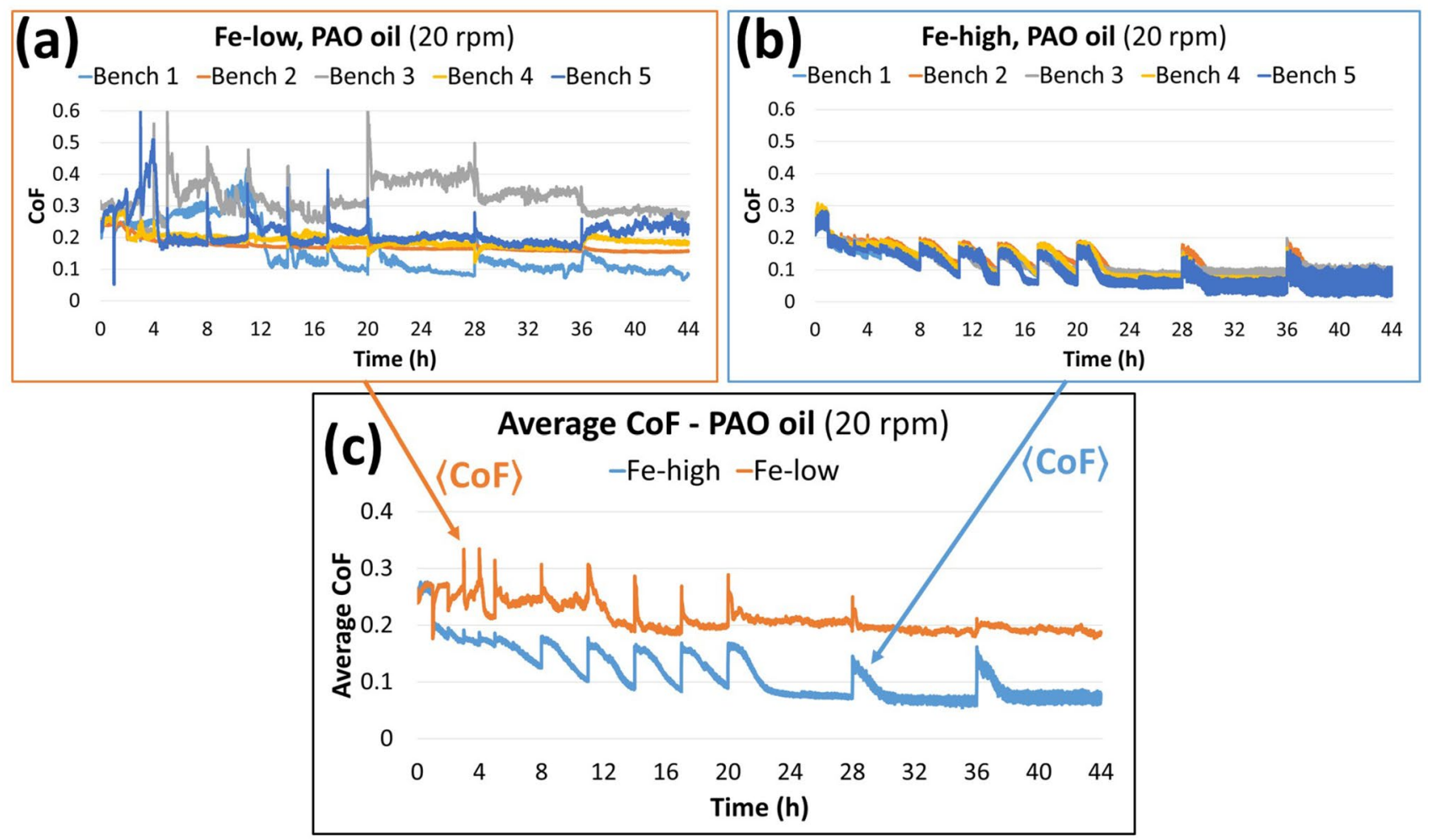

Fig. 8 Coefficient of friction variation over time for a low- (Fe-low) and $\mathbf{b}$ high-density (Fe-high) iron-based bearings using PAO lubricant and a speed saw ramp of $20 \mathrm{rpm}$. c Average values of friction curves ( 5 benches) 
wear response, see Figs. 6 and 7. Most specimens exhibited "regular" friction curves, as shown in Fig. 5, with an initial run-in, CoF spikes at expected time intervals due to test interruptions for Stribeck ramps, and finally a steady $\mathrm{CoF}$ state. For Fe-low (with PAO at $20 \mathrm{rpm}$ ), the CoF results did not follow this trend, see Fig. 8a and b, where the friction curves of the 5 parallel benches were plotted for Fe-low and compared to the "regular" curves obtained for Fe-high under the same testing conditions (PAO lubricant using $20 \mathrm{rpm}$ saw speed profile). The results of the 5 parallel benches were then averaged to scrutinize the overall friction trend, see Fig. 8c. Apart from producing significantly higher $\mathrm{CoF}$ than Fe-high, the Fe-low samples exhibited a greatly increased standard deviation in the CoF results, see Fig. 6a.

The friction coefficient was also evaluated during the Stribeck ramps after fixed testing times (13 in total, see Sect. 2.3). Stribeck curves were recorded three times in a row during every test interruption, where the data of the first one were discarded and the averaged values of the last two can be found in Fig. 9a and b. Note that Fe-low samples showed a typical Stribeck curve shape [33] at the very beginning of the test (after 1 and $2 \mathrm{~h}$ ), whereas after that the friction curves assumed unstable values during the exponential speed increase, see in Fig. 9a. This behavior is probably due to lack of lubricant film between the shaft and the inner bearing bore, in fact the $\mathrm{CoF}$ at high rotational speeds assumed similar values to those at the lowest speeds in the boundary lubrication regime. Higher values of friction at high speed $(\geq 1000 \mathrm{rpm}$ ) indicate more severe contact conditions and consequently higher wear rate, as observed in Fig. 7. On the other hand, Fe-high produced typical Stribeck curves in all the tests, see Fig. 9b. The Stribeck curves for Fe-high assumed lower and lower values with longer test duration, from a run-in stage a more steady one, see Fig. 9b, with the minimum $\mathrm{CoF}$ moving towards smaller speeds with increasing test duration. By contrast, for the Fe-low samples, the friction values in Stribeck curves generally increased over time and the minimum shifted towards higher speeds, indicating lubrication failure, see Fig. 9a.

The friction results of the Stribeck curves were also visualized as 2D heat maps. The vertical axis corresponds to the overall test time from top to bottom, and the horizontal one
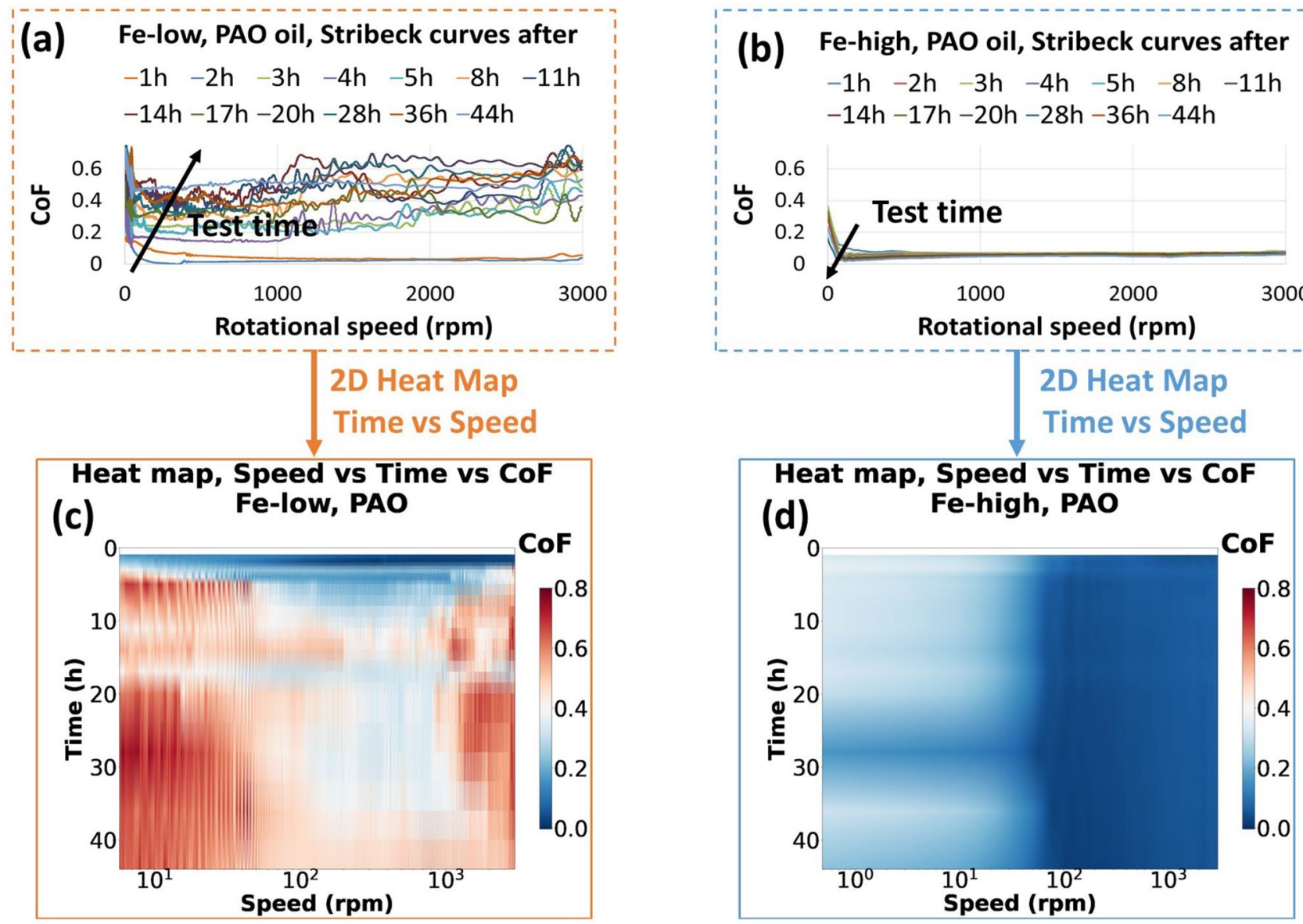

Fig. 9 Low- (Fe-low) and high-density (Fe-high) iron-based bearings using PAO lubricant: a, b Stribeck curves and $\mathbf{c}, \mathbf{d}$ heat maps (time $v s$ speed) 


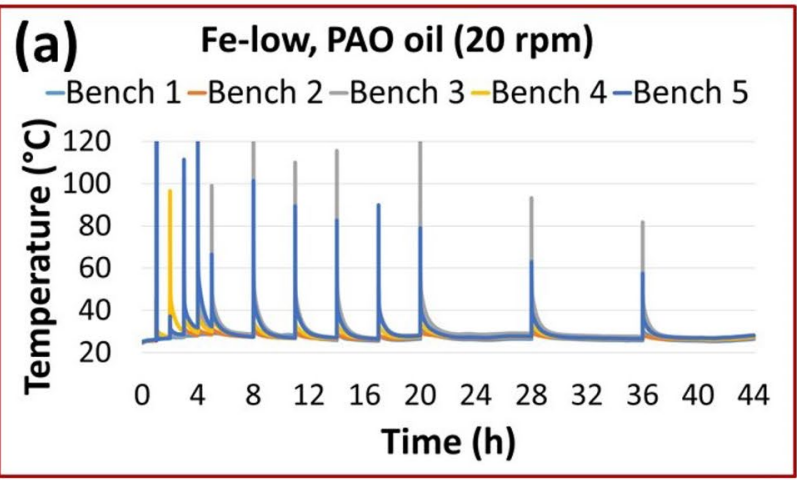

\section{(C) Fe-low, PAO+Gn oil (20 rpm)}

-Bench 1-Bench 2-Bench 3-Bench 4-Bench 5

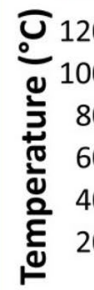

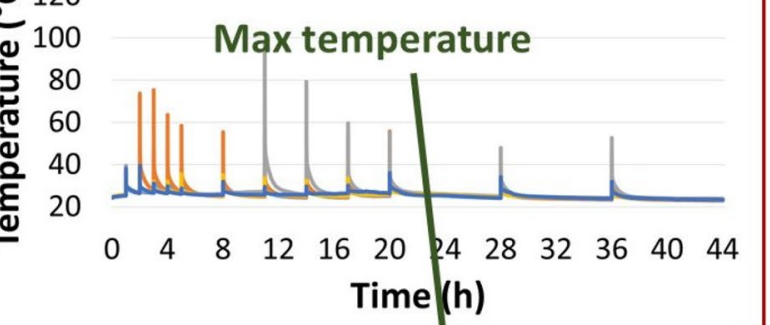

(e)

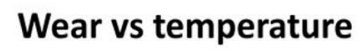

- Group 1 - Group 2

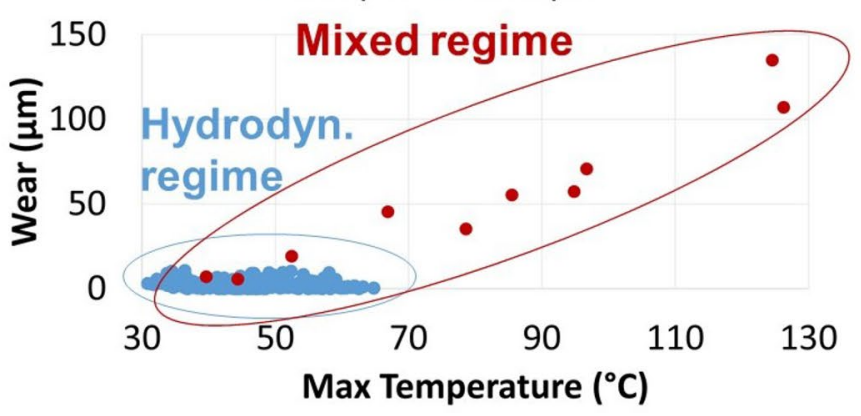

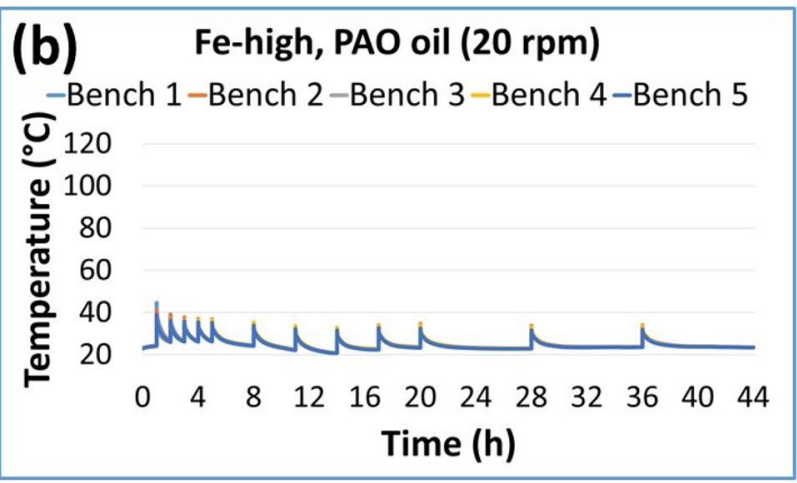

(d) Fe-high, PAO+Gn oil (20 rpm)

-Bench 1-Bench 2-Bench 3-Bench 4-Bench 5

O 120

100

$\begin{array}{ll}\stackrel{2}{5} & 80 \\ \text { ț } & 60\end{array}$

$\begin{array}{ll}\text { ๕ } & 40 \\ \text { ๕ } & 20\end{array}$

包

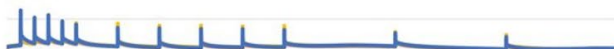

$\begin{array}{llllllllllll}0 & 4 & 8 & 12 & 16 & 20 & 24 & 28 & 32 & 36 & 40 & 44\end{array}$

Time (h)

(f)

Temperature vs CoF

-Group $1 \bullet$ Group 2 -Linear (Group 1)-Linear (Group 2)
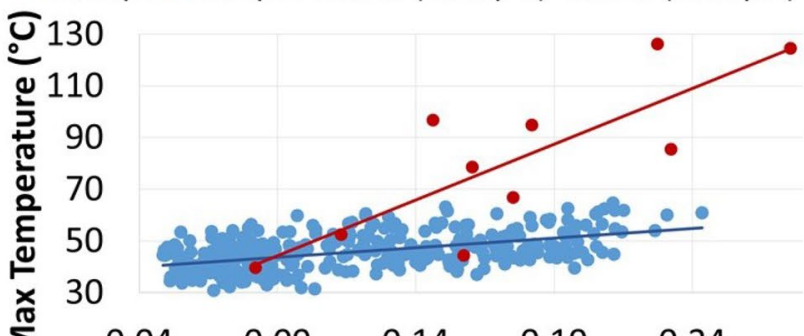

0.04

0.09

$0.14 \quad 0.19$

0.24

CoF (-)

Wear vs CoF

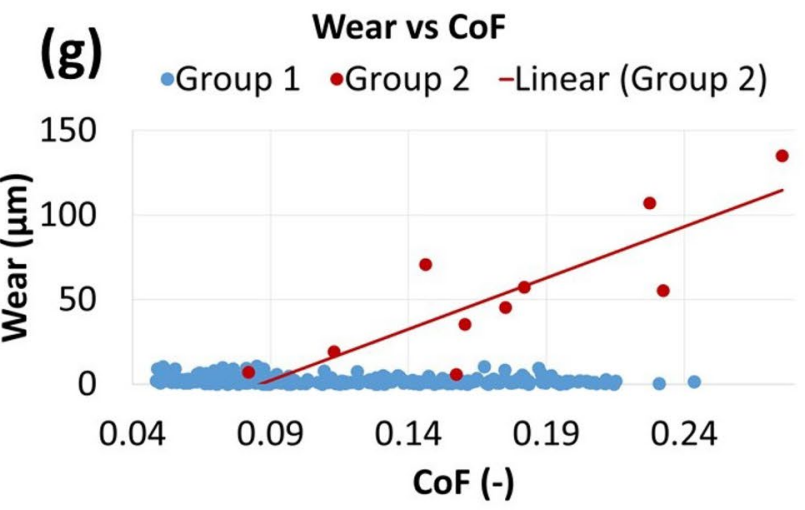

Fig. 10 Temperature variation during testing for $\mathbf{a}$ low- (Fe-low) and $\mathbf{b}$ high-density (Fe-high) iron-based material at $20 \mathrm{rpm}$ saw speed profile using PAO and $\mathbf{c}, \mathbf{d} \mathrm{PAO}+\mathrm{Gn}$. e, $\mathbf{f}, \mathbf{g}$ Wear, friction, and maximum temperature analysis for all material and lubricant combinations 
to the rotational speed, see Fig. $9 \mathrm{c}$ and $\mathrm{d}$. The speed axis was plotted using a logarithmic scale to highlight the differences in terms of CoF especially at low rotational speeds. Note that these maps only represent friction values during the Stribeck ramps and not the overall frictional behavior at $20 \mathrm{rpm}$. The heat map was drawn as interpolation of friction curves and visualizes their development over time. Results from $\mathrm{Fe}$ high and Fe-low were plotted using the same color scale to facilitate comparisons. From the heat maps, it becomes clear that Fe-low assumed low friction values at the beginning of the test, whereas friction subsequently increased during the test (vertical axis) and then also for higher rotational speeds (horizontal axis). On the other hand, Fe-high exhibited lower friction values during test and speed variation.

The temperature in the bearing was continuously measured at a sampling rate of $5 \mathrm{~Hz}$ during tests using a type $\mathrm{K}$ thermocouple. Results for iron-based materials (Fe-low and Fe-high) using PAO lubricants (PAO and $\mathrm{PAO}+\mathrm{Gn}$ ) are shown in Fig. 10a-d. It is possible to see a similar trend, namely that the temperature assumed steady values during the saw speed profile, as well as temperature spikes caused by the higher rotational speeds during the test interruptions for the Stribeck curves. Note that all four graphs in Fig. 10a-d were plotted using the same scale in the vertical axis (temperature); therefore, it is evident that temperature spikes reached higher values for Fe-low than for Fe-high with the same lubricant, probably due to lack of lubrication as explained in the previous section.

The wear measured at the end of the test was plotted over the maximum temperature reached during each experimental test, see Fig. 10e-g. From the graph, all experimental results could be divided into two groups depending on the relation between wear behavior and maximum temperature reached. The majority of the experiments lay on a wear plateau, where the increase of temperature (up to roughly $60^{\circ} \mathrm{C}$ ) did not significantly affect the wear behavior. By contrast, several experiments exhibited a linear correlation between maximum temperature and wear, where temperatures exceeding $60{ }^{\circ} \mathrm{C}$ led to unacceptable wear. It turns out that only the iron-based materials with low density (Fe-low), tested with PAO lubricants (PAO and $\mathrm{PAO}+\mathrm{Gn}$ ) at $20 \mathrm{rpm}$, belong to the latter group. When plotting the maximum temperature over the coefficient of friction for the two groups (Fig. 10f), although the data are quite scattered, it becomes clear that group 1 (blue) has a weak dependence of the temperature on the CoF, which is indicative of the corresponding systems achieving hydrodynamic lubrication. Here, the heating of the system is dominated by energy dissipation within the lubricant due to its viscosity. The slope of the CoF-vs-T relationship for the systems in group 2 (red) is almost 6 times as high as for group 1, which is evidence for operation in the mixed lubrication regime. Here, intermittent direct contact between asperities of the shaft and the bearing leads to plastic deformation, releasing higher amounts of energy, heating the system, thus thinning the lubricant and further reducing its load bearing capacity. When these deformation events become too severe, they result in wear and material loss. It may therefore be fallacious to assume that elevated temperature under mixed lubrication conditions causes wear, or that wear in the mixed lubrication regime causes the temperature to rise. Rather, both are correlated results of the direct asperity contact, which in turn are likely caused by a compound effect of a limited load bearing capacity of the lubricant at the low sliding speed combined with the high porosity of the bearing. Another possible explanation for the observed correlation may lie in the lubricant shear stress having a detrimental effect on the more fragile porous structure of the low-density bearings. This would lead to elevated amounts of debris accumulating in the lubricant, which may increase the friction and thus lead to the temperature increase.

Finally, plotting the diametric bearing wear over the $\mathrm{CoF}$ at the end of the test allows us to elucidate the common misconception that a high coefficient of friction automatically also leads to high wear. What Fig. 10g shows rather clearly is that in the overwhelming majority of cases, bearing wear is constantly below the negligibility threshold independent of the CoFs ranging from 0.04 to 0.24 , and that only for the high-temperature cases in the mixed lubrication regime, a distinct correlation between the two quantities is apparent.

To sum up, all the material and lubricant combinations led to acceptable tribological results, apart from Fe-low tested at $20 \mathrm{rpm}$ with PAO oils. A possible hypothesis could be based on the tribological effect of surface porosity on this particular combination. Even if Fe-low (high porosity) features lubricant reservoirs and good lubrication supply, it seems as if the presence of surface porosity combined with PAO lubricants brought drawbacks in terms of pressure build-up, thus resulting in less load carrying capacity, especially at elevated speeds.

\section{Conclusion}

We evaluated the tribological behavior of a wide range of bearing material and lubricant combinations in porous journal bearings at low sliding speeds. Parallel tests were performed with five identical pairings to obtain reliable results in reduced time. From this study, the following conclusions can be drawn:

- The experimental procedure adopted together with the use of the custom-made parallel test rig allowed a statistically sound scrutiny of the tribological behavior of PJBs 
in reduced testing time. This experimental workflow will improve the design and testing of PJBs.

- All bearing systems produced acceptable low wear after long tests with the exception of one category of samples (low-density iron-based) tested with PAO lubricants. Only this particular combination of oil, speed, material, and density (porosity) caused lubrication failure during the Stribeck ramps and consequently led to high wear. Changing at least one parameter between material, speed, lubricant, or bearing density already led to acceptable results.

- A direct relationship between maximum temperature after the Stribeck ramps and wear after the entire test was found. This behavior showed how severe wear and contact geometry variation during the Stribeck ramps could influence the contact geometry (less conformal) and consequently promote wear during the saw speed profile.

Acknowledgements This work was funded by the Austrian COMETProgram (Project InTribology1, No. 872176) and carried out at the "Excellence Centre of Tribology". The government of Lower Austria is gratefully acknowledged for financially supporting the endowed professorship tribology at the Vienna University of Technology (Grant No. WST3-F-5031370/001-2017) in collaboration with AC2T research $\mathrm{GmbH}$. The authors wish to thank Christoph Haslehner and Bettina Ronai for preparing the samples and running the tests, and Tobias Binder for image processing.

\section{Funding Open access funding provided by TU Wien (TUW).}

Open Access This article is licensed under a Creative Commons Attribution 4.0 International License, which permits use, sharing, adaptation, distribution and reproduction in any medium or format, as long as you give appropriate credit to the original author(s) and the source, provide a link to the Creative Commons licence, and indicate if changes were made. The images or other third party material in this article are included in the article's Creative Commons licence, unless indicated otherwise in a credit line to the material. If material is not included in the article's Creative Commons licence and your intended use is not permitted by statutory regulation or exceeds the permitted use, you will need to obtain permission directly from the copyright holder. To view a copy of this licence, visit http://creativecommons.org/licenses/by/4.0/.

\section{References}

1. Holmberg, K., Erdemir, A.: Influence of tribology on global energy consumption, costs and emissions. Friction 5(3), 263-284 (2017)

2. Mokhtar, M.O.A., Rafaat, M., Shawki, G. S.A.: Experimental investigations into the performance of porous journal bearings. SAE Technical Papers (1984)

3. Kaneko, S., Obara, S.: Experimental investigation of mechanism of lubrication in porous journal bearings: part 1-observation of oil flow in porous matrix. J. Tribol. 112(4), 618-623 (1990)

4. Meurisse, M.-H.: Porous Metal Journal Bearings, pp. 2669-2673. Springer, Boston (2013)
5. Morgan,VT., Cameron, A.: Mechanism of lubrication in porous metal bearings. In: Proceeding Conference on Lubrication and Wear, pp. 151-175 (1957)

6. Braun, A.L.: Porous bearings. Tribol. Int. 15(5), 235-242 (1982)

7. Neacşu, I.A., Scheichl, B., Vorlaufer, G., Eder, S.J., Franek, F., Ramonat, L.: Experimental validation of the simulated steadystate behavior of porous journal bearings. J. Tribol. 138(3), 031703 (2016)

8. Shi, F., Wang, Q.J.: A mixed-TEHD model for journal-bearing conformal contacts-part I: model formulation and approximation of heat transfer considering asperity contact. J. Tribol. 120(2), 198-205 (1998)

9. Wang, Q.J., Shi, F., Lee, S.C.: A mixed-TEHD model for journalbearing conformal contact-part II: contact, film thickness, and performance analyses. J. Tribol. 120(2), 206-213 (1998)

10. Skotheim, J.M., Mahadevan, L.: Soft lubrication: the elastohydrodynamics of nonconforming and conforming contacts. Phys. Fluids 17(9), 092101 (2005)

11. Zhu, Z., Nathan, R., Wu, Q.: Multi-scale soft porous lubrication. Tribol. Int. 137, 246-253 (2019)

12. Raman, R., Vinod Babu, L.: Tests on sintered bearings with reduced oil contents. Wear 95(3), 263-269 (1984)

13. Sharma, N., Kango, S., Sharma, R.K., Sunil, : Investigations on the effects of surface texture on the performance of a porous journal bearing operating with couple stress fluids. Int. J. Surf. Sci. Eng. 8(4), 392-407 (2014)

14. Amann, T., Kailer, A., Beyer-Faiß, S., Stehr, W., Metzger, B.: Development of sintered bearings with minimal friction losses and maximum life time using infiltrated liquid crystalline lubricants. Tribol. Int. 98, 282-291 (2016)

15. Trachsel, M., Pittini, R., Dual, J.: Evaluation and quantification of friction using ionic liquids in small, self lubricating journal bearings. Tribol. Int. 122, 15-22 (2018)

16. Eder, S.J., Bianchi, D., Neacşu, I.A., Vorlaufer, G.: An experimental and signal analysis workflow for detecting cold-induced noise emissions (cold squealing) from porous journal bearings. Mech. Syst. Signal Process. 115, 60-69 (2019)

17. Cameron, A., Morgan, V.T., Stainsby, A.E.: Critical conditions for hydrodynamic lubrication of porous metal bearings. Proc. Inst. Mech. Eng. 176(28), 761-770 (1962)

18. Eder, S.J., Ielchici, C., Krenn, S., Brandtner, D.: An experimental framework for determining wear in porous journal bearings operated in the mixed lubrication regime. Tribol. Int. 123, 1-9 (2018)

19. Ielchici, C.D., Krenn, S., Eder, S.J.: A tribometer and methodology for wear and friction testing of porous journal bearings at elevated temperatures. Ind. Lubr. Tribol. (2020). https://doi. org/10.1108/ILT-08-2019-0351/full/html

20. Boidi, G., Tertuliano, I.S., Cano, M.F., Machado, G.A.A., Souza, R.M., Machado, I.F.: Tribological evaluation of sintered and conventional gear materials. Technical Report, SAE Technical Paper (2017)

21. Boidi, G., da Silva Tertuliano, I., Lima, L.G.B.S., Profito, F.J., Machado, I.F.: Porosity effect of sintered steel on the frictional performance of conformal and nonconformal lubricated contacts. Tribol. Trans. 62(6), 1029-1040 (2019)

22. Ebner, M., Omasta, M., Lohner, T., Šperka, P., Krupka, I., Hartl, M., Michaelis, K., Höhn, B.-R., Stahl, K.: Local effects in EHL contacts with oil-impregnated sintered materials. Lubricants 7(1), 1 (2019)

23. Rasband, W.S., et al.: ImageJ (1997)

24. Bauer, P.: Grundlagen und Geräte der technischen Bohrungsmessung, vol. 17. Springer, Berlin (2013)

25. Souza, R.M., Ordoñez, M.F.C., Mezghani, S., Crequy, S., Fukumasu, N.K., Machado, I.F., El Mansori, M.: Orthogonal cut of SPS-sintered composites with ferrous matrix and FeMoS 
particles: numerical and experimental analysis. Tribol. Int. 149, $105750(2019)$

26. Vazirisereshk, M.R., Martini, A., Strubbe, D.A., Baykara, M.Z.: Solid lubrication with $\mathrm{MoS}_{2}$ : a review. Lubricants 7(7), 57 (2019)

27. Liu, S., Wang, Y., Muthuramalingam, T., Anbuchezhiyan, G.: Effect of $\mathrm{B}_{4} \mathrm{C}$ and $\mathrm{MoS}_{2}$ reinforcement on micro structure and wear properties of aluminum hybrid composite for automotive applications. Compos. Part B: Eng. 176, 107329 (2019)

28. Ebner, M., Lohner, T., Michaelis, K., Höhn, B.-R., Stahl, K.: Self-lubricating gears with oil-impregnated sintered materials. Forschung im Ingenieurwesen 81(2-3), 175-190 (2017)

29. Liu, X., Shi, X., Chaohua, W., Yang, K., Huang, Y., Deng, X., Yan, Z., Xue, B.: Tribological behavior of M50-MoS2 self-lubricating composites from 150 to $450{ }^{\circ} \mathrm{C}$. Mater. Chem. Phys. 198, 145-153 (2017)
30. Lancaster, J.K.: Transfer lubrication for high temperatures: a review. J. Tribol. 107(4), 437-443 (1985)

31. Tsuya, Y., Umeda, K., Kitamura, M.: Optimum concentration of solid lubricant in compact. Lubr. Eng. 32(8), 402-407 (1976)

32. Martin, J.M., Donnet, C., Le Mogne, T., Epicier, T.: Superlubricity of molybdenum disulphide. Phys. Rev. B 48(14), 10583-10586 (1993)

33. Hamrock, B.J., Schmid, S.R., Jacobson, B.O.: Fundamentals of Fluid Film Lubrication. CRC Press, Boca Raton (2004)

Publisher's Note Springer Nature remains neutral with regard to jurisdictional claims in published maps and institutional affiliations. 